\title{
Evaluation of Normal, Branched Paraffin Hydrocarbons and Some Unsaturated Aliphatic Hydrocarbons In Cigarette Smoke by Class Capillary Columns
}

\author{
by N. Carugno and S. Rossi \\ Laboratorio Chimico dei Monopoli, Rome, Italy
}

\section{INTRODUCTION}

In a previous study (2), stress has been laid upon the utility of gas chromatographic glass capillary columns for the evaluation of polynuclear hydrocarbons in cigarette smoke condensate by using both a flame ionization and an electron capture detector.

It has been deemed advisable to extend the application of this research method to the evaluation of other compounds present in the neutral fraction of cigarette smoke as normal, branched paraffin hydrocarbons and some unsaturated aliphatic hydrocarbons.

Carruthers and Johnstone (4) reported a gas-liquid chromatographic analysis of cigarette smoke wax where the peaks corresponding to the compounds $C_{30}, C_{31}$ and $C_{33}$ were composed of two unresolved peaks. Alike, one of us (3) had not obtained a good separation of branched paraffins from the normal homologues by using padked columns. Spears and Lassiter (12), Mold et al. (10) succeeded in identifying by gas chromatography the alkanes and branched alkanes subsequent to their molecular sieve treatment; this process, however, involves two different chromatographies. These last few works revealed the presence of both iso and anteiso paraffin hydrocarbons in several types of tobacco with anteiso series mainly consisting of homologues with an even number of carbon atoms.

The analysis of fractions containing different classes of unsaturated aliphatic hydrocarbons in cigarette smoke condensate has been reported by numerous workers $(1,5,6,7,8,9,11,13)$.

This paper describes the conditions used for the evaluation of normal and branched paraffin hydrocarbons as also the first investigations on fractions containing unsaturated aliphatic hydrocarbons.

APPARATUS

Two Fractovaps Carlo Erba, a Model $C$ and a Model D linear temperature programmed, equipped with a flame ionization detector and an electron capture detector were used in this work. The Model D was connected to a Westronics Dualchannel Recorder. The glass capillary column $65 \mathrm{~m}$. long and of $0.30 \mathrm{~mm}$. internal diameter was coated with SE 52 (methylphenylsilicone).

The following chromatographic conditions were used:

a) Isotherm : column temperature : $290^{\circ} \mathrm{C}$, injection temperature : $340^{\circ} \mathrm{C}$, carrier gas : nitrogen at an inlet pressure of $0.65 \mathrm{~atm}$;

b) Linear programmed temperature : $100^{\circ} \mathrm{C}$ to $300^{\circ} \mathrm{C}$, rate $1.8^{\circ} \mathrm{C} / \mathrm{min}$., injection temperature $: 340^{\circ} \mathrm{C}$, carrier gas : nitrogen at an inlet pressure of $0.65 \mathrm{~atm}$.

Samples of 1 to $4 \mu \mathrm{l}$ were injected as solutions in tetrahydrofuran or hexane with a Hamilton syringe and with a split ratio of $60: 1$.

* Presented at the 4th International Scientific Tobacco Congress, Athens, September 1966. 
Six hundred non-filter cigarettes were smoked on an automatic smoking machine according to CORESTA standard procedures. The condensate was collected in cooled traps $\left(-80^{\circ} \mathrm{C}\right)$ and removed therefrom with $600 \mathrm{ml}$ of ethanol-hexane (2:1) and after $200 \mathrm{ml}$ of water were added. The following phases of the procedure are similar to those previously reported in detail (2).

Briefly, this method consists in purifying the concentrated hexane-extracts by two chromatographies on silica gel $\left(10 \% \mathrm{H}_{2} \mathrm{O}\right)$, eluting with hexane $(1000 \mathrm{ml})$ and with hexane-benzene $(500 \mathrm{ml} \mathrm{I:9}+500 \mathrm{ml} \mathrm{8:2)}$ and extracting with $2 \mathrm{~N}$ sodium hydroxide and perchloric acid $\mathrm{I:I}$ after the first chromatography.

The eluates of the second chromatography were concentrated to dryness separately and the residues were then dissolved with $30 \mathrm{ml}$ of hexane and extracted six times with nitromethane. The nitromethane solutions were used for the investigations on polynuclear hydrocarbons.

Both hexane fractions called fractions 1 and 2 respectively were evaporated to dryness and diluted with tetrahydrofuran.

Equal portions of the aforesaid two solutions were united and treated with ethyl alcohol at $-5^{\circ} \mathrm{C}$. Four crystallizations were carried out with a view to obtaining a very clear paraffin wax. The crystallization residues gave a yellow oil.

The paraffin wax and the yellow oil were denominated fraction A and fraction B respectively. All the four fractions were then examined by gas chromatography.

All the fractions were later brominated : they were diluted in $20 \mathrm{ml}$ of hexane; a $1 \%$ bromine chloroform solution was added in drops up to a slight excess. After a few hours, the exceeding bromine was eliminated by extracting the hexane solution with thiosulphate $0,1: N$. The solutions were then washed with water and after drying over the sodium sulphate, evaporated to dryness in vacuum and diluted to $0.2 \mathrm{ml}$ with tetrahydrofuran.

\section{RESULTS AND DISCUSSION}

Figures $I$ and 2 show the chromatograms of a standard mixture of n-alkanes in isotherm at $290^{\circ} \mathrm{C}$ and in linear programmed temperature from $100^{\circ} \mathrm{C}$ to $300^{\circ} \mathrm{C}$ then continuing in isotherm. $\mathrm{A}$ temperature of $290^{\circ} \mathrm{C}$ in isotherm was selected in order to emphasize the peaks corresponding to hydrocarbons with a high number of carbon atoms.

Figures 3 and 4 show the chromatograms of the fraction $\mathrm{A}$ of cigarette smoke condensate containing the normal and branched paraffin hydrocarbons.

In this connection, it is noted that, by using capillary columns, a good separation of the branched paraffins (marked b) from the normal paraffins is obtained with no resort to the previous treatment with molecular sieves.

Our analysis reveal the presence of normal paraffins starting from $C_{21}$, although those corresponding to $C_{21}, C_{22}, C_{28}$ and $C_{24}$ are present in small quantities, and of branched paraffins starting from $C_{28}$ with the prevalence of normal series for the compounds with odd numbers of carbon atoms and of branched series for the compounds with even numbers of carbon atoms.

The presence was also noted in this fraction, though in small quantities (attenuation $1 \times 2$ ) of other compounds with a number of carbon atoms higher than $C_{94}$.

They do not give any response to the electron capture detector and do not disappear after bromuration, which means that they are unsaturated hydrocarbons. Their retention indices correspond to the compounds up to $\mathrm{C}_{41}$.

It seems that, starting from $\mathrm{C}_{34}$, for some of these compounds three peaks are obtained, that is, two branched paraffins and the normal one, but, under these operational conditions, no indication is possible by gas dromatography to distinguish the iso series versus the anteiso series.

Most of these compounds, after $\mathrm{C}_{34}$, are eluted in the fraction 2 (Fig. 7 ).

Figures 6 and 7 show the chromatograms of the fraction 1 and fraction 2 respectively, before the crystallization phase. In these analyses a flame ionization detector and an electron capture detector were used. Besides the normal and branched paraffins, some unsaturated compounds are present in these fractions; in effect, many peaks disappear after bromuration. Most of these compounds are present in the fraction $B$ too. 
The dhromatogram of the fraction 2 (Fig. 7) shows many components sensible to the electron capture detector. The same thing occurs, though in a different way, in the dromatogram of the fraction B (Fig. 5). Therefore, the fractions examined contain some compounds sensible to electron capture which, in our opinion, might not always be identified with unsaturated hydrocarbons, considering that the most part of the latter show a slight response to the above detector.

The presence of the unsaturated hydrocarbons was better emphasized by the disappearance of many peaks after bromuration.

In effect, in the fraction A (Figures 3 and 4 ) no peak disappears after the bromine treatment. On the contrary, after brominating the oil fraction (Fig. 5) many peaks disappear the main ones of which correspond to retention temperatures of $151^{\circ}, 163^{\circ}, 170^{\circ}, 172^{\circ}, 215^{\circ}, 216^{\circ}, 252^{\circ}, 254^{\circ}, 263^{\circ}$, $265^{\circ}, 268^{\circ}, 270^{\circ} \mathrm{C}$. Among these components, neophytadiene and squalene were identified.

In the fraction 1 too (Fig. 6), the disappearance of some peaks is noted, chiefly those corresponding to neophytadiene and squalene.

In the fraction 2 (Fig. 7), the disappearing peaks, because of the addition of bromine to the double bonds, are more than $50 \%$.

The analyses of the fraction B, 1 and 2, with the electron capture detector, after the bromine treatment, were not taken into consideration for the high number of peaks, due to the impurities and the small molecules, probably produced by the double bond breaking which may occur, though to a small extent, during the reaction with bromine. All these impurities containing a halogen atom, become extremely sensible to the electron capture detector, while they are not evidenced by the hydrogen flame detector.

The fraction A, also after bromuration, did not give, as it was foreseen, any response to the electron capture detector.

CONCLUSIONS

Owing to the high efficiency of glass capillary columns, both normal and branched paraffin hydrocarbons present in cigarette smoke condensate can, at the same time, be identified and determined by gas chromatography.

According to the results of the first analyses carried out on fractions containing unsaturated hydrocarbons, the above capillary columns can be considered as a useful and efficient tool to examine cigarette smoke components together with other techniques such as the infrared spectrometry and mass spectrometry.

SUMMARY

Gas : chromatographic analyses of normal and branched paraffin hydrocarbons of cigarette smoke condensate were performed with SE 52 coated glass capillary columns using a flame ionization detector and working in isotherm temperature and in linear programmed temperature. This investigation was extended to fractions containing unsaturated aliphatic hydrocarbons, by using in this case both an electron capture detector and a flame ionization detector. Some chromatograms are reported.

ZUSAMMENFASSUNG

Die gaschromatographische Analyse normaler und verzweigter Paraffine im Rauchkondensat von Cigaretten wurde unter Benutzung von Glaskapillarsäulen, die mit SE 52 beschichtet waren, durchgeführt. Es wurde ein Flammen-Ionisationsdetektor eingesetzt und sowohl unter isothermen Bedingungen als auch bei linear programmierter Temperatur gearbeitet. Fraktionen von ungesättigten aliphatischen Kohlenwasserstoffen wurden durch gleichzeitige Verwendung eines ElektroneneinfangDetektors (electron capture detector) und eines Flammen-Ionisationsdetektors untersucht. Einige Gaschromatogramme werden mitgeteilt. 
Avec des colonnes capillaires en verre recouvertes de SE 52 et par l'emploi d'un détecteur à ionisation de flamme opérant à températures isothermes et à température linéaire programmée, on a effectué des analyses par chromatographie en phase gazeuse des paraffines normales et ramifiées contenues dans le condensat de la fumée de cigarette. On a étendu ces recherches aux hydrocarbures aliphatiques non saturés, en utilisant également un détecteur à capture d'électrons. On présente quelques chromatogrammes.

REFERENCES

1. Black, D. K., and Dickens, F.: Chemistry and Industry 1965, 197.

2. Carugno, N., and Rossi, S.: Evaluation of Polynuclear Hydrocarbons in Cigarette Smoke by Glass Capillary Column, in the press.

3. Carugno, N.: National Cancer Institute Monography No. 9 (1962) 171.

4. Carruthers, W., and Johnstone, R. A. W.: Nature 10 (1959) 1131.

5. Dare, D. L., Entwistle, I. D., and Johnstone, R. A. W.: Chemistry and Industry 1966, 629.

6. Entwistle, I. D., and Johnstone, R. A. W.: Chemistry and Industry 1965, 269.

7. Gladding, R. N., and Wartam, W. B.: J. Org. Chem. 24 (1958) 1358.

8. Kosak, A. J., and Swinehart, J. S.: Chemistry and Industry 1958, 1007.

9. Johnstone, R. A. W., and Quan, P. M.: J. Chem. Soc. 1963, 5706.

10. Mold, J. D., Stevens, R. K., Means, R. E., and Ruth, J. M.: Biochemistry 2 (1963) 606.

11. Rodgman, A., Lawrence, C. C., and Mins, S. S.: J. Org. Chem. 26 (1961) 497.

12. Spears, A. W., Lassiter, C..W., and Bell, J. H.: Journal of Gas Chromatography 1 (1963) 3437.

13. Van Duuren, B. L., and Schmitt, F. L.: Chemistry and Industry 1958, 1006.

The authors' address:

Laboratorio Chimico, Monopoli di Stato, Piazza Mastai 11, Rome, Italy

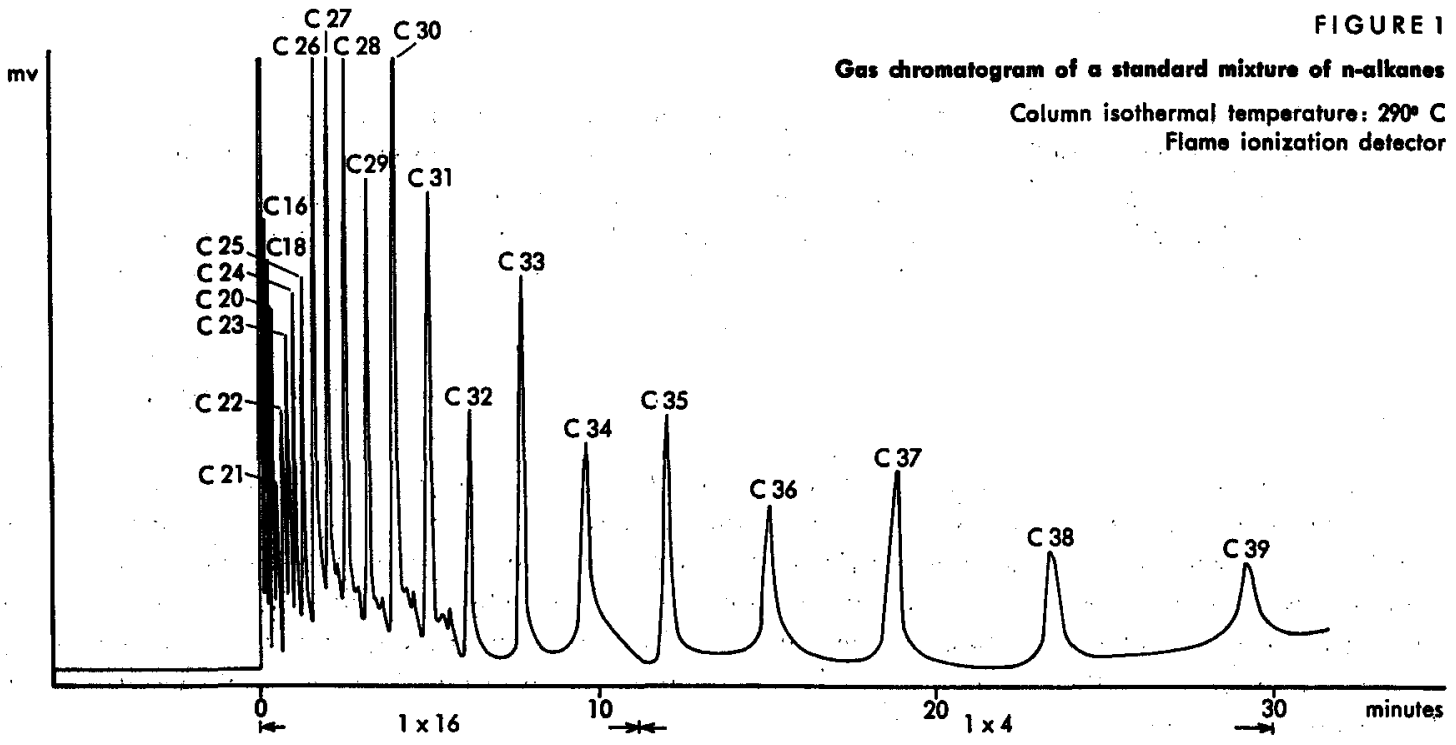



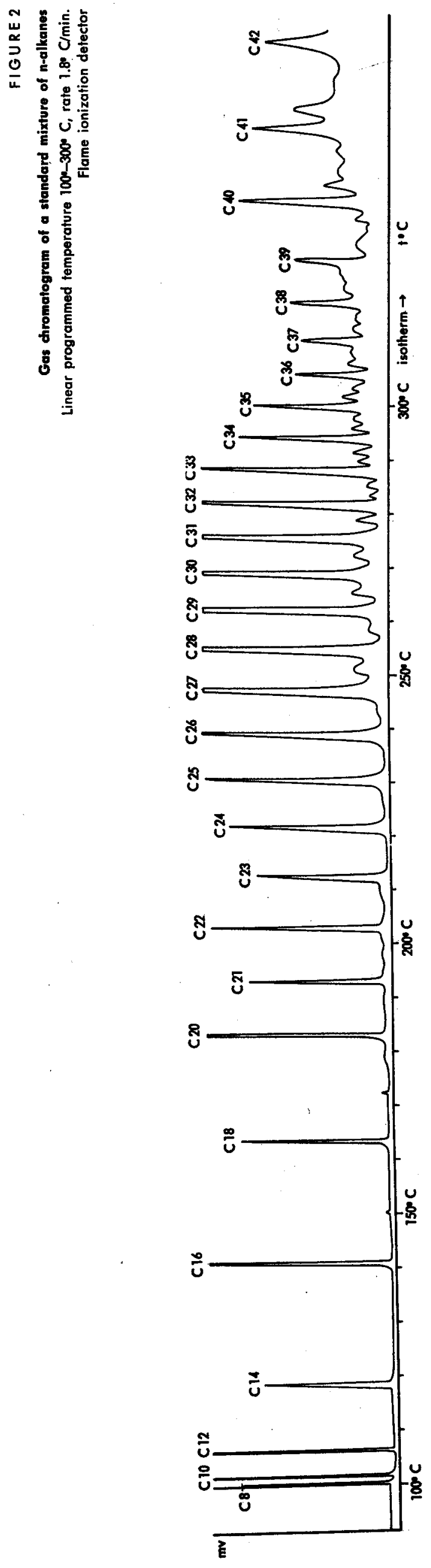

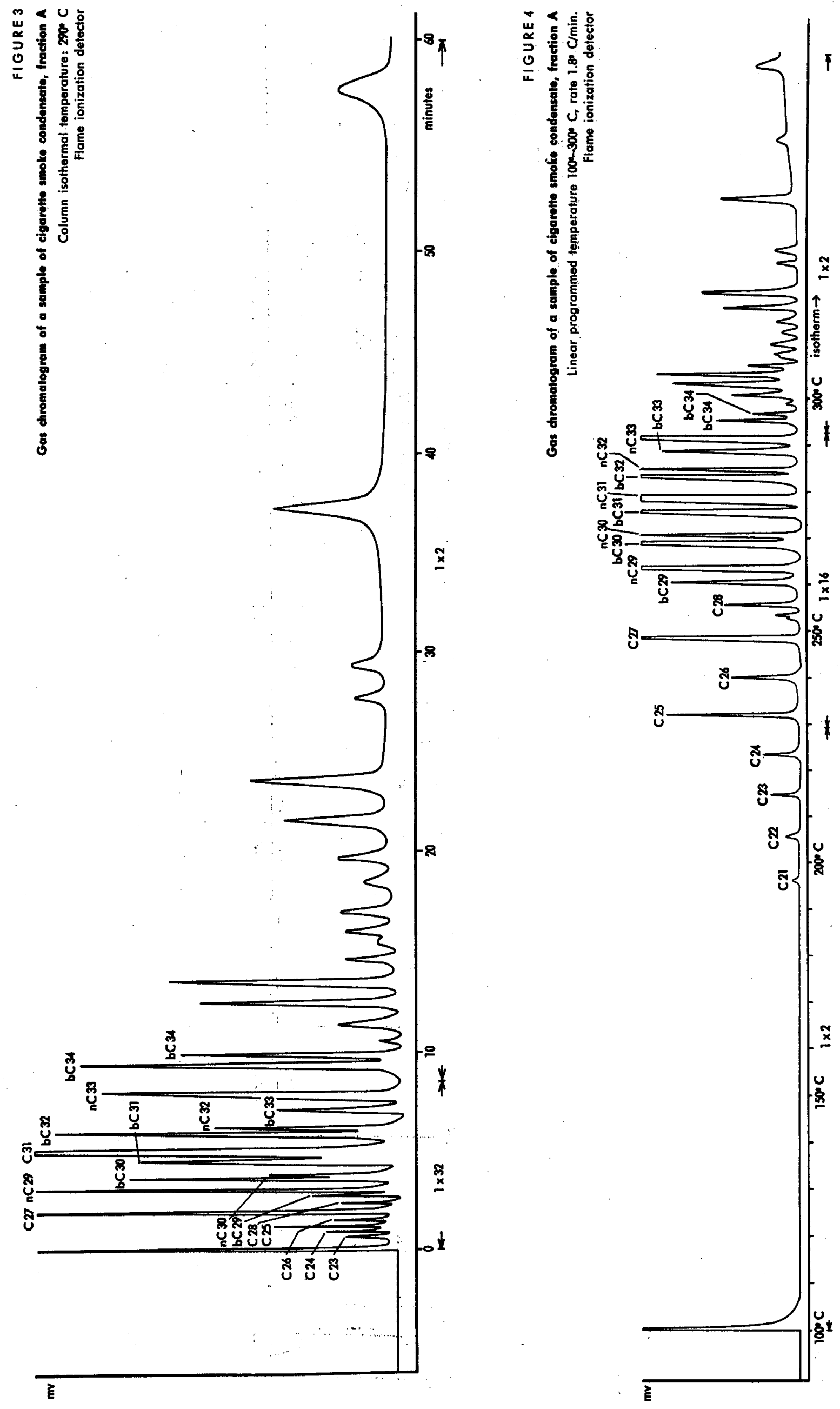

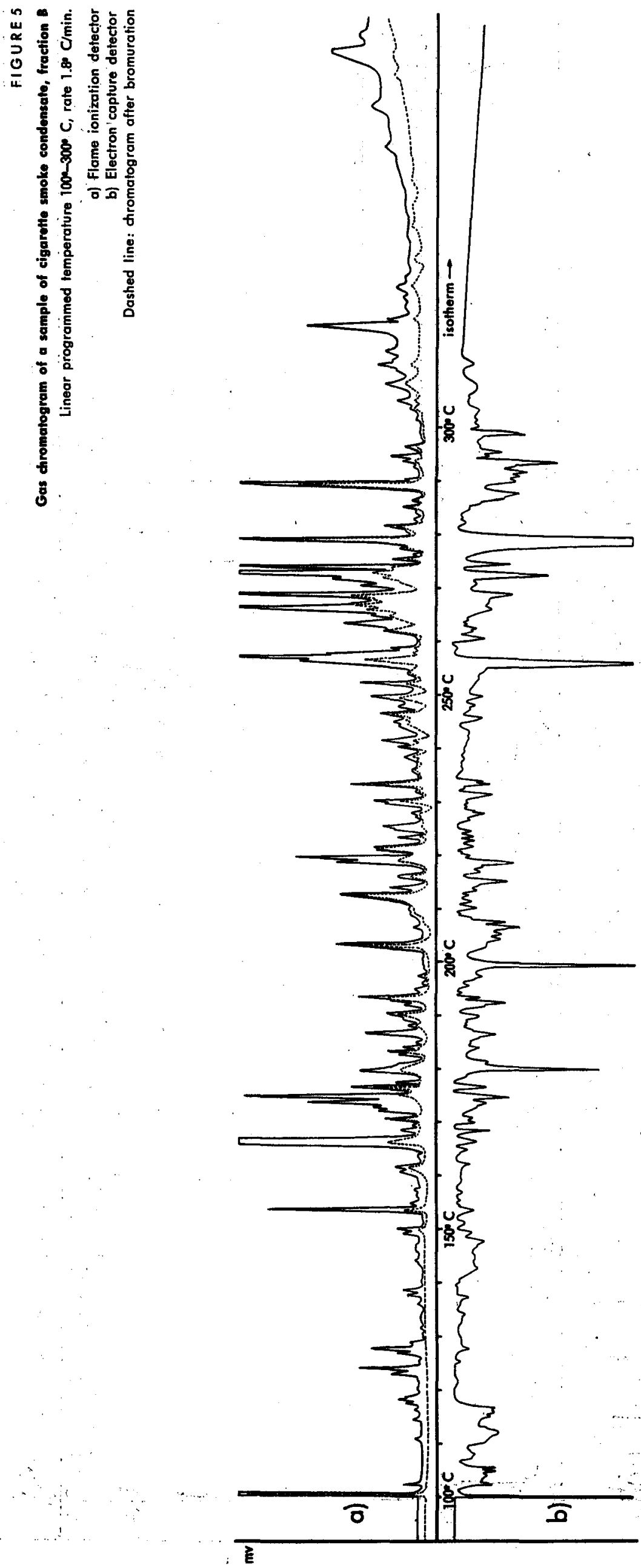

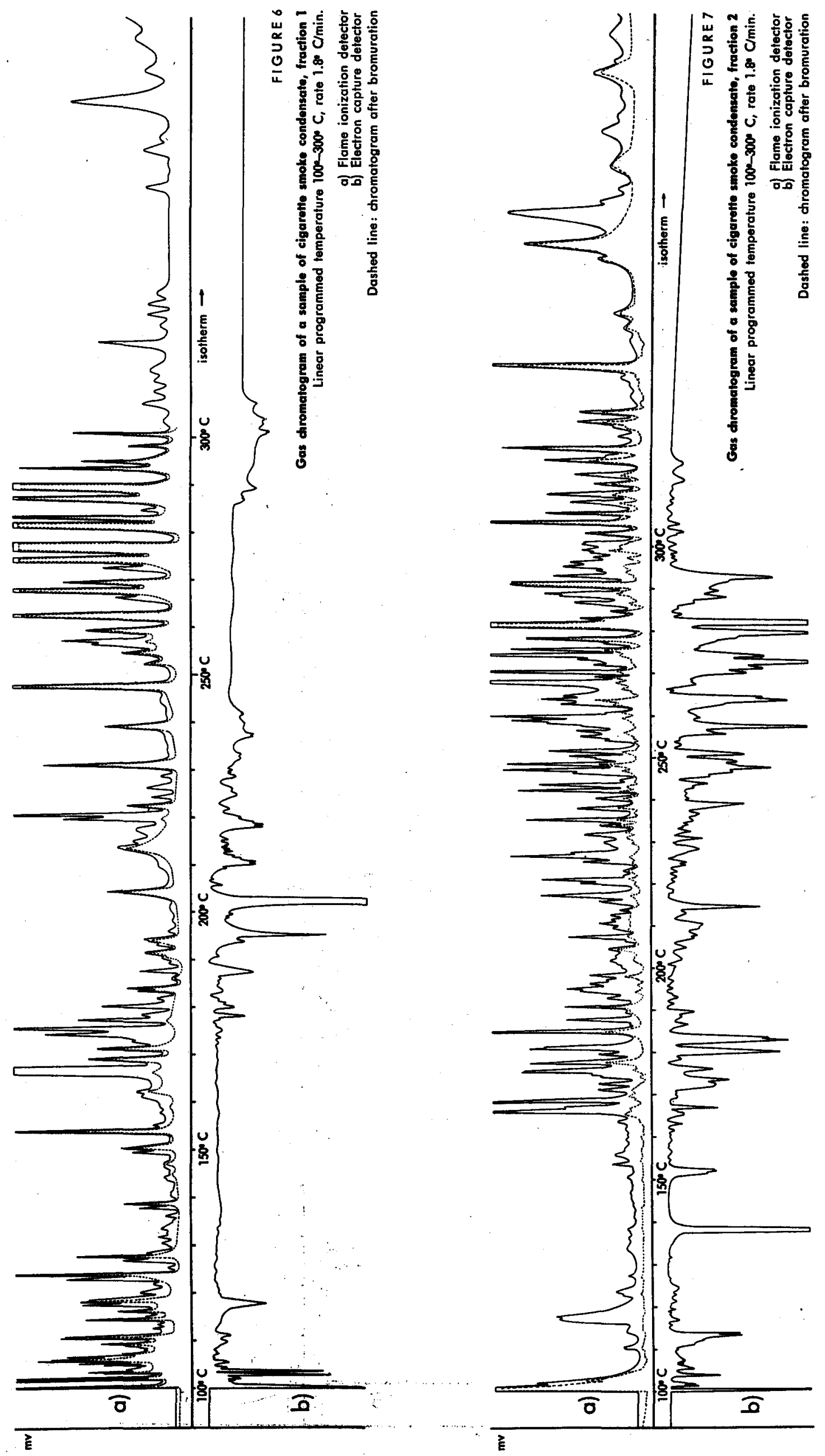